\title{
Access to Non-Communicable Disease (NCD) Services Among Urban Refugees and Asylum Seekers, Relative to the Thai Population, 2019: A Case Study in Bangkok, Thailand
}

\author{
Mathudara Phaiyarom (ID) \\ Hathairat Kosiyaporn' \\ Nareerut Pudpong ${ }^{1,2}$ \\ Pigunkaew Sinam' \\ Rapeepong Suphanchaimat (D) ${ }^{1,3}$ \\ Sataporn Julchoo $\mathbb{D}^{\prime}$ \\ Watinee Kunpeuk (ID) \\ 'International Health Policy Program, \\ Ministry of Public Health, Nonthaburi, \\ I I000, Thailand; ${ }^{2}$ Sirindron College of \\ Public Health, Chonburi, Thailand; \\ ${ }^{3}$ Division of Epidemiology, Department of \\ Disease Control, Ministry of Public \\ Health, Nonthaburi, II000, Thailand
}

Correspondence: Mathudara Phaiyarom International Health Policy Program, Ministry of Public Health, Nonthaburi I 1000 , Thailand

Tel +6625902382

Fax +6625902385

Email mathudara@ihpp.thaigov.net
Background: The health of urban refugees and asylum seekers (URAS) in Thailand has been under-researched compared with other groups of non-Thai populations, especially in the area of chronic non-communicable diseases (NCD). The objectives of this study were to i) examine NCD prevalence; ii) access to NCD services; and iii) factors associated with access to NCD services among urban refugees and asylum seekers (URAS) in comparison with the Thai population.

Methods: A cross-sectional study, using a self-administrative questionnaire adapted from the Thai Health and Welfare Survey (HWS), was conducted in 2019. URAS were randomly selected from the register of the Bangkok Refugee Center. One hundred and eighty-one URAS participated in the survey. The data were combined with 2941 Thai records from the HWS. The population scope was confined to Bangkok. Bivariate analysis by Chi-square, Fisher's exact, and Mann-Whitney $U$-tests was conducted to examine difference in demographic and access to NCD services between URAS and Thais. Multivariable logistic regression was performed to identify factors associated with access to NCD services.

Results: Overall, URAS were young, less educated, and poorer than Thais. The trend of NCDs was similar to the Thai population, except mental health disorders appeared to be more prevalent in URAS. Almost half of the URAS did not receive any formal treatment. Being insured, abiding with Buddhism, and living in more affluent households were factors associated with better access to NCD services. URAS from Asian countries had greater access to NCD care than those from non-Asian countries.

Conclusion: Policymakers should consider expanding the insurance coverage to URAS, similar to coverage for Thai populations. Additional studies on refugees' health status and service utilization in other settings outside Bangkok are strongly recommended.

Keywords: urban refugee, asylum seeker, NCD, healthcare, Thailand

\section{Background}

Global human mobility is increasing for several reasons, including people searching for better education or better economic opportunities and escaping political violence and armed conflicts. In 2017, the estimated number of international cross-border populations amounted to 258 million or $3.4 \%$ of the total global population. ${ }^{1}$ Of these people, 68 million were forcibly displaced people. Among these, 25 million were refugees and 3 million were asylum seekers. ${ }^{2}$ The refugee and asylum seekers' situations received much attention in recent years after 5.5 million 
Syrian refugees fled to Europe $^{3}$ and almost a million Rohingyas sought refuge in Bangladesh during 2015$2017 .^{4}$

Refugees' health has been discussed in numerous highlevel international meetings for years, for example the World Health Assembly (WHA) Resolution 70.15, ${ }^{5}$ the New York Declaration for Refugees and Migrants ${ }^{6,7}$ and the Global Compact on Refugees in $2018 .^{8}$

Thailand is one of the common cross-border destinations in Southeast Asia. The number of non-Thais in Thailand were estimated at approximately 4.9 million people in 2018, mostly from neighbouring countries, including Cambodia, Lao PDR, Myanmar, and Viet Nam, the so-called CLMV nations. ${ }^{9}$ Also, more than 120,000 refugees and asylum seekers lived in temporary sheltered areas along the border.

Compared to migrant workers from CLMV nations, refugees and asylum seekers' health seemed to be off the political radar. This situation was more pronounced for refugees in urban setting.

This is because the situation of refugees in temporary shelters is well known by local healthcare providers and the United Nations High Commissioner for Refugees (UNHCR) and international non-governmental organizations (NGOs) have provided humanitarian assistance for years. ${ }^{10,11}$ In contrast, about 5000 urban refugees and asylum seekers (URAS) are not covered by any public health insurance and there is no clear public agency mandated to take care of their well-being. In addition, most URAS face many difficulties in accessing health services, including barriers caused by poverty, language, and culture. ${ }^{12,13}$ Some government officers were not even aware of the existence of URAS. ${ }^{12}$

The issue of non-communicable diseases (NCDs) is a significant and growing health trend worldwide. About $70 \%$ of global mortality was attributed to NCDs in 2020 . NCDs also caused 16 million premature deaths, of which four-fifths NCD occurred in low- and middle-income countries. ${ }^{13,14}$ In the South-East Asia Region (SEAR), NCDs were responsible for almost two-thirds of all deaths (or about 8.9 million deaths) with 4.4 million deaths occurring prematurely. ${ }^{15}$ In Thailand, it was estimated that NCDs accounted for $74 \%$ of total mortality. The leading causes of NCD deaths in 2016 were cardiovascular diseases $(23 \%)$, cancers $(18 \%)$, chronic respiratory diseases $(6 \%)$, and diabetes $(4 \%){ }^{16}$

As a vulnerable population, refugees and asylum seekers have a higher risk of developing physical and mental disorders. ${ }^{17-19}$ Susceptibility to several chronic diseases, including hypertension, diabetes, and cancers can be attributed to the stress which results from leaving their origin country. ${ }^{20,21}$ Their general lifestyle, such as dietary intake and activity level has changed, therefore, they are at increased risk of NCDs. ${ }^{22,23}$ A high NCD prevalence among refugees and asylum seekers was reported in many studies. Previous literature revealed that $77 \%$ of all deaths of displaced Syrians were explained by NCDs. ${ }^{24,25}$ Similarly, Iraqi, Afghan, and Palestinian refugees in in the Middle East were reported to face a high NCD burden. ${ }^{26}$ The high prevalence of NCDs faced by refugees and asylum seekers poses a challenge to health systems in host countries especially low- and middle-income countries (LMIC) due to the cost of providing continuous care for chronic health conditions. ${ }^{27,28}$

Despite evidence of the NCD burden, infectious diseases receive more public health attention from host countries and health research on this population has also mainly focused on communicable diseases. ${ }^{29-31}$ However, little is known about NCD prevalence and the access to NCD services among URAS especially in the Thai context. Therefore, this study aimed to: (i) explore NCD prevalence; (ii) determine access to NCD services; and (iii) explore factors associated with access to NCD services among URAS in contrast to the Thai population.

\section{Methods}

\section{Study Design}

A cross-sectional study was performed. A structural questionnaire was used for a primary survey on URAS living in Bangkok during October to December 2019. The questionnaire was modified from the Health Welfare Survey (HWS), which is a national representative survey for monitoring the health status of Thai citizens, conducted by the National Statistical Office of Thailand. We also combined data from the primary survey on URAS with existing HWS data of Thai citizens in Bangkok in 2019.

In terms of the survey process, first, we communicated with the Bangkok Refugee Centre (BRC), an agency working in collaboration with UNHCR, which provides patronage for URAS. We focused on the top-ten nationalities of URAS in Thailand from the BRC list, namely: Pakistani, Vietnamese, Cambodian, Somali, Afghan, Palestinian, Chinese, Sri Lankan, Iraqi, and Syrian. The total of URAS from these top-ten nationalities in the BRC list was 3021 . Then, we sampled 206 URAS from the pool 
on the BRC list (for more details of sample size calculation, see the later section: "Sample size calculation and sampling methods"). Of these 206 samples, 181 completed the questionnaire. Finally, we combined the survey data with the Thai HWS data $(n=2941)$. Therefore, the final dataset comprised 3122 observations.

\section{Sample Size Calculation and Sampling Methods}

Since the prevalence of NCD was the most interesting indicator for sample size calculation, the following formula, $n=\frac{\left(Z_{1-\frac{\alpha}{2}} \sqrt{2 P Q}+Z_{1-\beta} \sqrt{P_{1} Q_{1}+P_{2} Q_{2}}\right)^{2}}{\left(P_{1}-P_{2}\right)^{2}}$, was applied. We used $\alpha=0.05 ; \beta=0.2 ; Z_{1-\frac{\alpha}{2}}=1.96 ; Z_{1-\beta}=0.84 ; P_{1}=$ 0.218, $Q_{1}=1-P_{1} ; P_{2}=0.096, Q_{2}=1-P_{2} ; \mathrm{P}=\left(P_{1}+P_{2}\right) / 2$ and $\mathrm{Q}=1$-P. $P_{1}$ refers to the NCD prevalence of URAS. $P_{2}$ refers to the NCD prevalence in Thais. According to the recent report by the Ministry of Public Health (MOPH) of Thailand, the NCD prevalence in Thai adults was $9.6 \%{ }^{32}$ Therefore, $P_{2}$ was substituted by 0.096 . As there has been no previous study on NCDs among URAS in Thailand, we used NCD prevalence among urban refugees in other settings instead. A study by Rehr et al reported that the prevalence of NCDs in urban refugees in northern Jordan was $21.8 \%$. Thus, we replaced 0.218 for $P_{1}{ }^{28}$ After accounting for $10 \%$ incomplete information, we needed at least 171 participants in each sample group (URAS and Thais).

URAS were included in the study using stratified random sampling with probability proportional to size (PPS) approach. We considered age, sex, and nationality during the selection process; see Table 1S.

We expanded the sample size to 200 instead of 171 as the BRC staff informed the research team that they could recruit approximately 200 participants. After the survey was conducted, 181 participants had completed the questionnaire with sufficient data for further analysis. The number of Thai participants in the HWS dataset already outnumbered the calculated samples.

\section{Data Collection}

We performed a survey on URAS from October to December 2019. All participants were asked to travel to the BRC office to complete the paper questionnaire. A stipend was given to cover the travel cost (about US\$ 10 each). For those who were not able to travel to BRC, a phone interview was conducted instead. Parents or legal guardians were allowed to respond on behalf of a child aged below 15 years. A verbal interview was performed for those who had difficulty reading instead of a written questionnaire. It took approximately thirty minutes on average to complete the questionnaire. Before the survey took place, a meeting was held between the research team and BRC staff and the URAS volunteers $(\mathrm{n}=30)$ who agreed to participate in the survey. This process was done in order to fine tune understandings about the questionnaire, as part of face validity check.

\section{Questionnaire Design and Interested Determinants}

The questionnaire for URAS was adapted from the HWS questionnaire, and consisted of two key domains: (i) demographic characteristics and (ii) questions on NCDs.

Questions in the first domain were composed of sex, age, education background (primary level, secondary level, and degree or above), religious affiliation (Buddhism, Christ, Muslim, and others), insurance status (insured [with either public or private insurance] and uninsured); and household monthly income. We categorized age into groups $(\leq 15$ years, $>15$ years, $\leq 60$ years, and $>60$ years) and divided the variable household monthly income into two divisions, "about-or-equal average" and "below average", using the figure of 45,707 Baht (US\$ 1428) - the mean monthly income of a household in Bangkok according to the National Statistical Office (NSO) - as a reference. ${ }^{33}$

Questions in the second domain asked a respondent whether he or she was suffering from NCDs or was ever diagnosed with an NCD before. Those with NCDs were requested to answer a few more questions: "Did you receive treatment for the last bout of sickness?" and "What is the main facility where you received NCD services?" Choices for answers were provided, for instance, "did not get treatment", "self-treatment", "visit public hospital or clinic", and "visit private hospital or clinic". Note that the questionnaire was translated according to the participants' first language (such as Arabic, Chinese or Vietnamese).

\section{Statistical Analyses}

All analyses were performed by Stata v14.0 (StataCorp LP, serial number: 401406358220). The analyses were divided into two sections: (i) descriptive statistics and (ii) inferential analysis. For descriptive statistics, all categorical 
variables were displayed in the forms of frequency and percentage. Age and household economy were expressed as median and percentile. For inferential analysis, the bivariate analysis, including Chi-square, Fisher's exact and Mann-Whitney $U$-tests, were performed to identify the demographic difference between URAS and Thais and the relationship between the access to NCD services and each demographic variable.

A multivariable logistic regression was performed because the dependent variable was in the form of binary outcome and in this step, we included all key independent variables at once. In this step, we re-classified the variable about access to services into two tiers: "did not receive treatment or self-treatment" and "accessing services in institutional care". The selected independent variables were those showing P-value less than 0.2 in the bivariate analysis. Crude and adjusted odd ratios (OR) with 95\% confidence interval $(95 \% \mathrm{CI})$ were presented.

Further, we performed subgroup analysis but this time focused on URAS data only. We replaced the insurance variable with the nationality variable, namely, Asian versus non-Asian. The subgroup analysis was conducted in the same fashion as the main analysis.

\section{Results}

\section{Demographic Characteristics}

There were 3122 records included for the analysis (181 URAS participants and 2941 Thai participants). The maleto-female ratio was about 0.9 in both Thais and URAS. The majority of the URAS had completed up to primary education (63.5\%) while most Thais had achieved secondary level $(38.5 \%)$. The majority of Thais were Buddhist (97.1), whereas more than three-quarters of URAS were Muslim (48.1\%). The median age of URAS was about 23 years with the majority in the working age group (15-60 years), while the median age of Thais was 42 years with almost one-fifth in the elderly group. Almost all URAS (98.7\%) had less household monthly income than the Thai average. Approximately $98 \%$ of URAS were uninsured with any insurance schemes. In contrast, over $99 \%$ of Thai participants were covered by either public or private insurance. All of these demographic variables, except sex, showed statistically significant difference, Table 1.

\section{Prevalence of NCD}

There was no significant difference in NCD prevalence between Thais and URAS $(21.8 \%$ and $21.2 \%$, respectively). The majority of those reporting the presence of NCD had only one disease and approximately a quarter of them reported having three or more diseases, see Table 2. The top-three most commonly reported diseases among URAS were hypertension (6.6\%), mental disorders $(5.5 \%)$ and diabetes $(3.3 \%)$. When the analysis for each disease was tallied, URAS significantly suffered from mental disorders in comparison with Thai participants (P-value $<0.001)$. The situation was in stark contrast with hyperlipidemia, which showed in Thais at a greater extent than URAS (P-value $=0.014)$, see Figure 1 .

\section{NCD Service Access}

NCD service access demonstrated a marked difference between Thais and URAS (P-value < 0.001). More than half of Thai participants visited public hospitals or clinics (57.5\%). Only $2.2 \%$ of Thais did not receive or seek any treatment, whereas approximately $11 \%$ of URAS fell in the group of no treatment. About one-third (31.6\%) of the URAS exercised self-treatment, about a three times greater percentage than Thais, see Figure 2. It should be noted that Figure 2 was based on the exclusion of missing data in Thai participants which accounted for $35 \%$ of the observations reporting the presence of NCDs (with no missing records in URAS). Accordingly, we explored the demographic of two groups: those with and without missing data. There was no difference between the two datasets in terms of demographic profile; see Table 2S. Later, we replaced the missing records in Thais with the same proportion of treatment modalities in non-missing records. However, the P-value in this analysis remained less than 0.001 like the P-value in the complete case analysis; see Figure 3.

\section{Determinants of NCD Services Access}

Being insured had a strong and significant association with NCD care access in bivariate analysis (Crude OR $=5.0$, P-value $<0.001$ ), however, it turned out to be not significant in multivariable logistic regression although the direction of association was still greater than one (adjusted OR $=1.7, \mathrm{P}$-value $=0.475$ ). Religion and household economy exhibited a significant association with NCD care access in bivariate analysis $(\mathrm{P}$-value $<0.001$, and $\mathrm{P}$-value $=0.011$, respectively); see Table 3 . We also explored the interaction between insurance and age groups. There was no marked difference between the analysis with interaction terms and the analysis without; see Table $3 \mathrm{~S}$. 
Table I Demographic Characteristics of the Participants

\begin{tabular}{|c|c|c|c|c|}
\hline Variable & Thai $(n=294 I)$ & URAS $(n=181)$ & P-value & Test \\
\hline Sex-n (\%) & & & 0.975 & Chi-square \\
\hline - Female & $1550(52.7)$ & $95(52.5)$ & & \\
\hline - Male & |39| (47.3) & $86(47.5)$ & & \\
\hline Education-n (\%) & & & $<0.001$ & Chi-square \\
\hline - Up to primary & $981(34.6)$ & 115 (3.5) & & \\
\hline - Up to secondary & I09I (38.5) & $46(25.4)$ & & \\
\hline - Degree or above & $765(26.9)$ & $20(11.1)$ & & \\
\hline Religion-n (\%) & & & $<0.001$ & Chi-square \\
\hline - Buddhism & $2857(97.1)$ & $16(8.8)$ & & \\
\hline - Christ & $6(0.2)$ & $67(37.0)$ & & \\
\hline - Muslim & $75(2.55)$ & $87(48.1)$ & & \\
\hline - Others & $3(0.1)$ & II (6.I) & & \\
\hline Median age-years (P25, P75) & $42.0(25.0,56.0)$ & $23.1(10.4,37.7)$ & $<0.001$ & Mann-Whitney U \\
\hline Age group-n (\%) & & & $<0.001$ & Chi-square \\
\hline$\bullet \leq 15$ years & 349 (11.9) & $68(37.6)$ & & \\
\hline - $>15$ but $\leq 60$ years & $2033(69.1)$ & $102(6.3)$ & & \\
\hline$\bullet>60$ years & $599(19.0)$ & II (6.I) & & \\
\hline Median household income-Baht (P25, P75) & $30,000(15,000,45,000)$ & $6000(4000,9000)$ & $<0.001$ & Mann-Whitney U \\
\hline Household economy & & & $<0.001$ & Fisher's exact \\
\hline - Above average & $27 \mid(3.9)$ & $2(1.3)$ & & \\
\hline - Below average & $861(76.1)$ & I5I (98.7) & & \\
\hline Insurance status & & & $<0.001$ & Fisher's exact \\
\hline - Uninsured & $6(0.2)$ & I $77(97.8)$ & & \\
\hline • Insured & $2935(99.8)$ & $4(2.2)$ & & \\
\hline
\end{tabular}

Table 2 Chronic Non-Communicable Diseases (NCD) of the Participants

\begin{tabular}{|c|c|c|c|c|}
\hline Variable & $\begin{array}{c}\text { Thai } \\
(n=294 I)\end{array}$ & $\begin{array}{l}\text { URAS } \\
(n=\mid 8 I)\end{array}$ & $P$-value & Test \\
\hline $\begin{array}{l}\text { Having at least } \\
\text { one disease }\end{array}$ & $642(21.8)$ & $38(2 \mid .2)$ & 0.085 & Chi-square \\
\hline $\begin{array}{l}\text { Number of } \\
\text { diseases-n (\%) } \\
\text { - } 1 \\
\text { - } 2 \\
\text { - } \geq 3\end{array}$ & $\begin{array}{l}375(58.4) \\
185(28.8) \\
82(12.8)\end{array}$ & $\begin{array}{c}25(65.8) \\
7(18.4) \\
6(15.8)\end{array}$ & 0.376 & Chi-square \\
\hline
\end{tabular}

Subgroup analysis with a focus on the URAS population found that Asian URAS had greater odds of accessing NCD services than non-Asian URAS (adjusted OR $=13.8$, P-value $=0.129$ ). Christian and Muslim URAS were more likely to access NCD care than Buddhist URAS. In contrast, low education background was associated with poor NCD care access (adjusted OR $=0.1, \mathrm{P}$-value $=0.147$ ); Table 4 .

\section{Discussion}

This is one of the few studies to explore NCD prevalence and access to NCD services among URAS in Thailand, and the paper helps increase the richness of academic analysis in the field of migrant health. Based on a brief exploration of literature on MEDLINE, using search terms "Thailand" and "Refugees", we found no quantitative research related to health services among URAS in Thailand, and none focused on NCDs. Therefore, this study is among the very first to demonstrate quantitative evidence in support of healthcare for NCDs among URAS. It is hoped that policymakers can use the findings of this research to inform policy decisions, such as using the number of URAS to estimate the resources needed to provide healthcare for this particular population. We will discuss policy implications in later paragraphs.

One of the distinct features of this study is the integration of data on Thai populations from a previous HWS with the survey on URAS. The results 


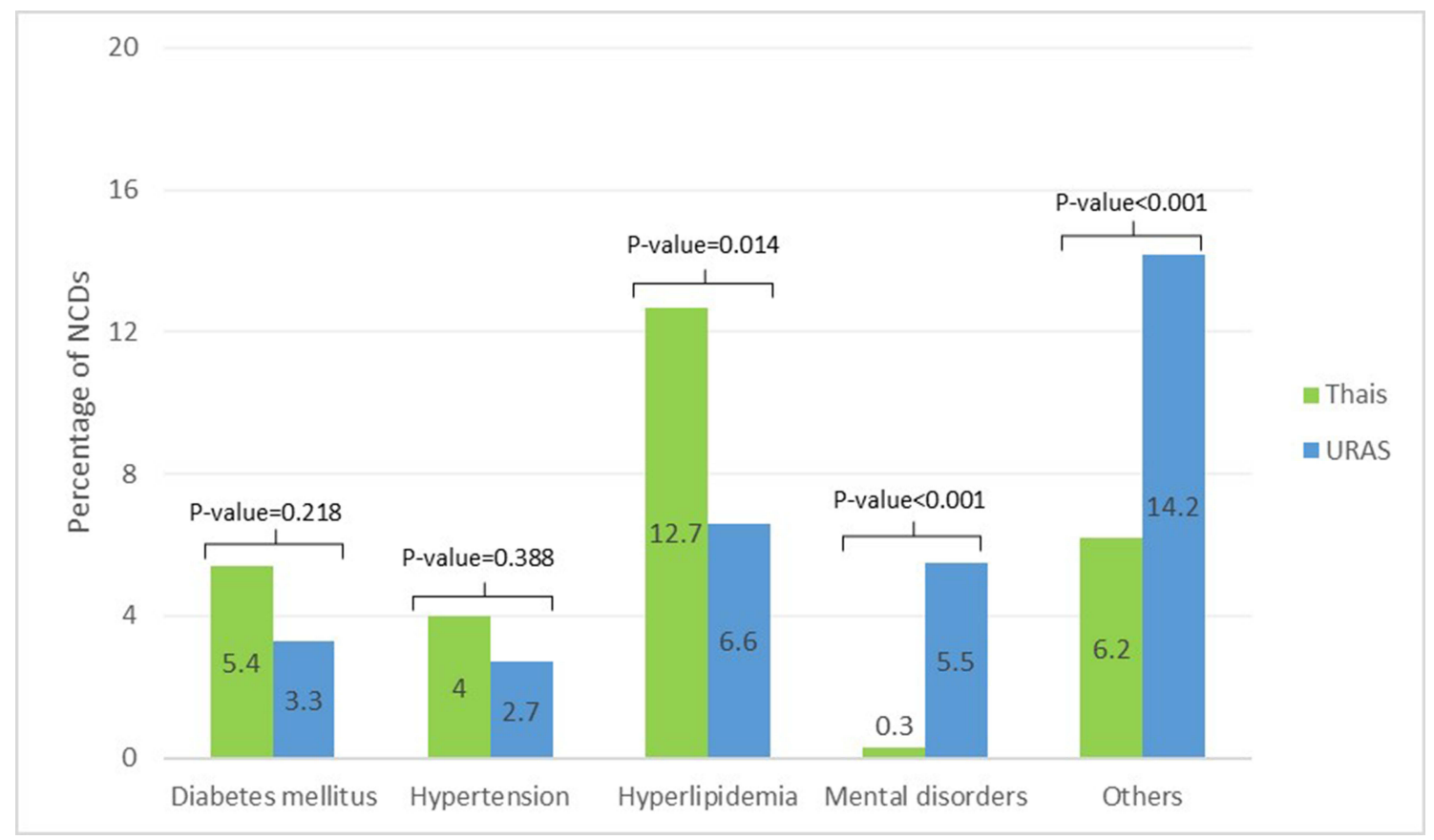

Figure I Prevalence of NCD, tallied by diseases.

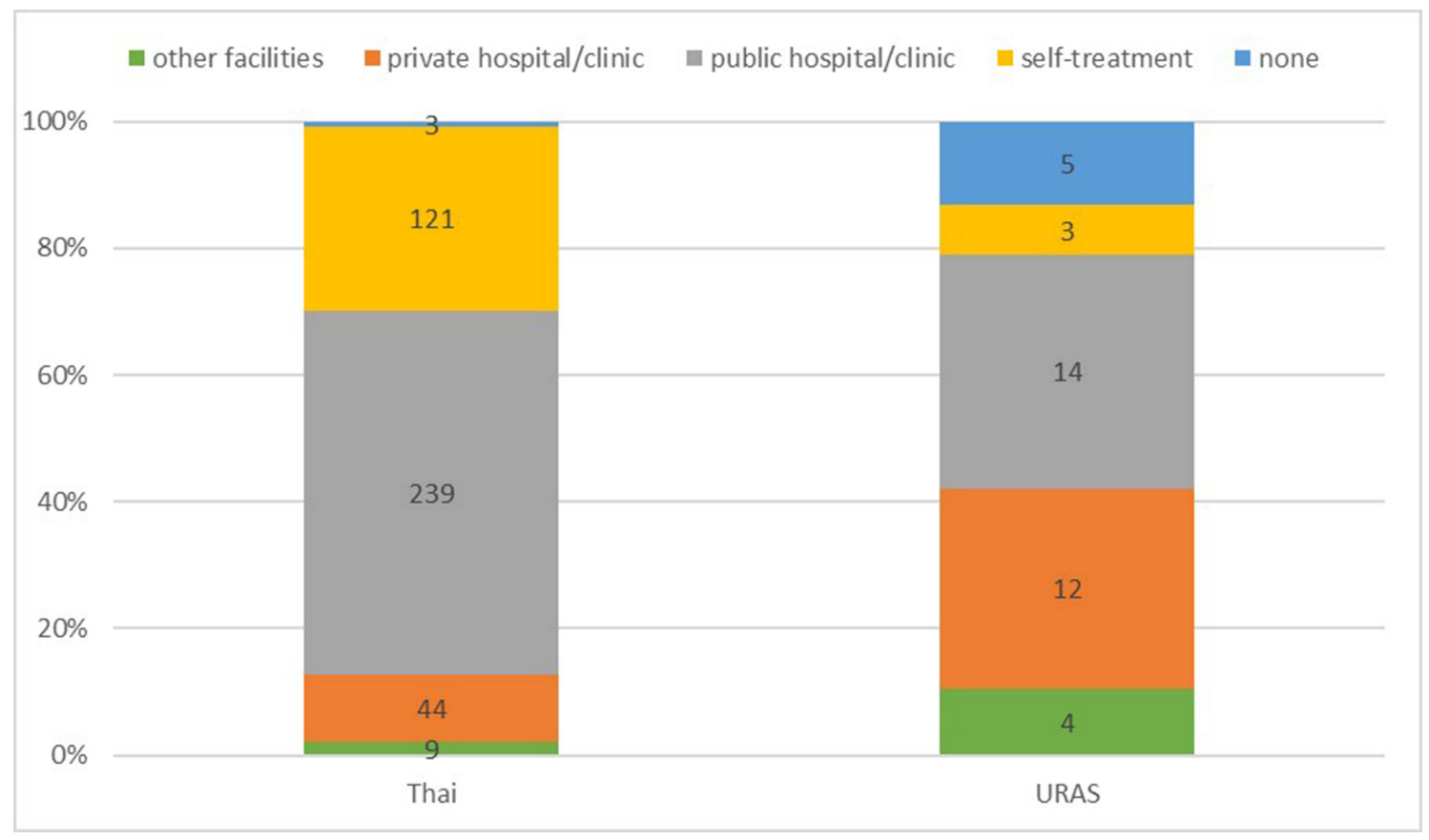

Figure 2 Prevalence of NCD service access by participant groups (excluding missing records). Note: P-value $<0.001$ by Fisher's exact test.

suggested that most URAS were in working age group, had lower education, and experienced financial difficulty. Also, almost all of them were uninsured by any insurance scheme. The prevalence of NCDs among the URAS showed a similar trend with the Thai population, however, the prevalence of mental illness was higher among URAS. Many foreign studies also pointed to the same direction. For instance, Shawyer et al demonstrated that about half of asylum seekers in Australia faced mental illness. ${ }^{34}$ Similarly, a study in the US 


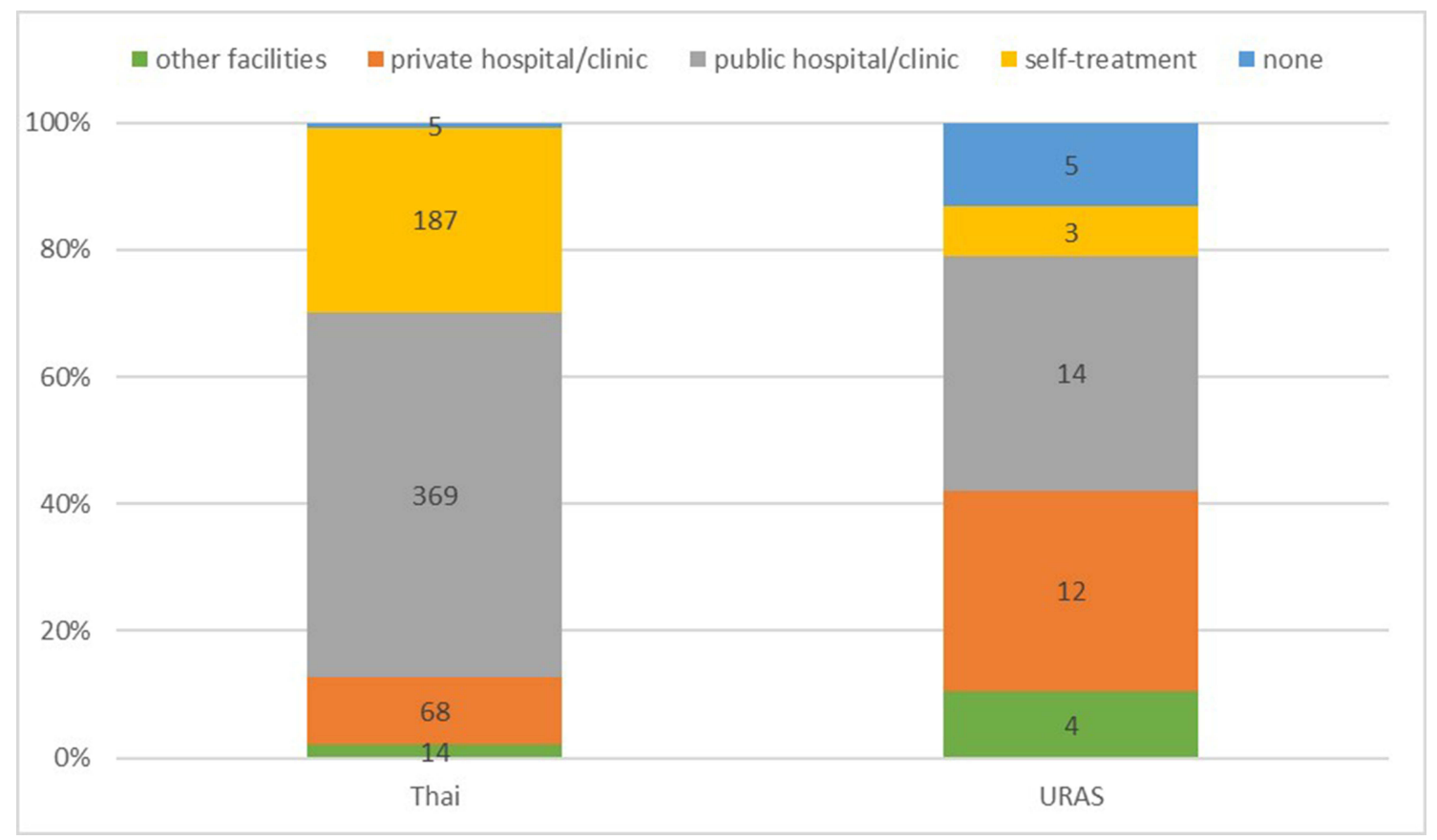

Figure 3 Prevalence of NCD service access by participant groups (replacing of missing records with the same proportion of treatment modalities in non-missing records). Note: P-value $<0.00$ I by Fisher's exact test.

found that half of Iraqi refugee women experienced anxiety, depression, and emotional stress. ${ }^{35}$

Another distinct finding is although the NCD prevalence between URAS and Thais was nearly at the same level, about half of URAS did not receive any treatment or were only self-treated. This finding was in stark contrast with the Thai participants, where $90 \%$ had ever attended institutional care. This result was consistent with a study by UNHCR using a Health Access and Utilization Survey (HAUS) in 2015, which revealed that approximately $27 \%$ of URAS in Malaysia with chronic disease were unable to find treatment. ${ }^{36}$

From the analysis above, factors that determine better access to NCD services were being insured, having faith in

Table 3 Factors Associated with NCD Care Access

\begin{tabular}{|c|c|c|c|c|}
\hline \multirow[t]{2}{*}{ Factors } & \multicolumn{2}{|c|}{$\begin{array}{c}\text { Bivariate Analysis by Chi } \\
\text { Square Test }\end{array}$} & \multicolumn{2}{|c|}{$\begin{array}{c}\text { Multivariable Logistic } \\
\text { Regression }\end{array}$} \\
\hline & Crude OR $(95 \% \mathrm{Cl})$ & P-value & Adjusted OR (95\% Cl) & P-value \\
\hline Insured ( $v$ uninsured) & $5.0(2.5-10.1)$ & $<0.001$ & $1.7(0.4-6.9)$ & 0.475 \\
\hline Male ( $v$ female) & $0.8(0.5-1.3)$ & 0.364 & - & 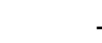 \\
\hline \multicolumn{5}{|l|}{ Age group ( $v \leq 15$ years) } \\
\hline$\bullet>15$ but $\leq 60$ years & $1.2(0.3-4.4)$ & 0.817 & $1.3(0.3-6.2)$ & 0.749 \\
\hline - $>60$ years & $2.6(0.7-10.0)$ & 0.170 & $2.5(0.5-12.0)$ & 0.258 \\
\hline \multicolumn{5}{|l|}{ Religious ( $v$ Buddhist) } \\
\hline - Christ & $0.2(0.1-0.4)$ & $<0.001$ & $0.4(0.1-1.9)$ & 0.232 \\
\hline - Muslim & $0.3(0.1-0.7)$ & 0.006 & $0.6(0.2-1.8)$ & 0.350 \\
\hline \multicolumn{5}{|l|}{ Education level ( $v$ primary education) } \\
\hline - Secondary education & I.I $(0.6-1.9)$ & 0.832 & $1.2(0.6-2.3)$ & 0.551 \\
\hline - Degree of above & $1.7(0.8-3.7)$ & 0.178 & $1.9(0.8-4.3)$ & 0.126 \\
\hline Below-average household monthly income (v about-or-above average) & $0.5(0.3-0.9)$ & 0.011 & $0.8(0.4-1.4)$ & 0.386 \\
\hline
\end{tabular}


Table 4 Factors Associated with NCD Care Access Among URAS

\begin{tabular}{|c|c|c|c|c|}
\hline \multirow[t]{2}{*}{ Factors } & \multicolumn{2}{|c|}{$\begin{array}{c}\text { Bivariate Analysis by Chi } \\
\text { Square Test }\end{array}$} & \multicolumn{2}{|c|}{$\begin{array}{c}\text { Multivariable Logistic } \\
\text { Regression }\end{array}$} \\
\hline & Crude OR $(95 \% \mathrm{Cl})$ & P-value & Adjusted OR (95\% Cl) & P-value \\
\hline Asian (v non-Asian) & $4.8(0.5-51.7)$ & 0.191 & $13.8(0.5-405.9)$ & 0.129 \\
\hline Male ( $v$ female) & $0.7(0.9-5.6)$ & 0.736 & - & - \\
\hline \multicolumn{5}{|l|}{ Age group ( $v \leq 15$ years) } \\
\hline - $>15$ but $\leq 60$ years & $\mathrm{N} / \mathrm{A}$ & N/A & N/A & $\mathrm{N} / \mathrm{A}$ \\
\hline - $>60$ years & N/A & N/A & N/A & N/A \\
\hline \multicolumn{5}{|l|}{ Religious ( $v$ Buddhist) } \\
\hline - Christ & $17(0.6-523.8)$ & 0.105 & $10.0(0.3-327.3)$ & 0.193 \\
\hline - Muslim & $8(0.3-184.4)$ & 0.194 & $3.2(0.1-94.2)$ & 0.499 \\
\hline \multicolumn{5}{|l|}{ Education level ( $v$ primary education) } \\
\hline - Secondary education & $0.2(0.0-2.0)$ & 0.157 & $0.1(0.0-2.3)$ & 0.147 \\
\hline - Degree of above & N/A & $\mathrm{N} / \mathrm{A}$ & N/A & N/A \\
\hline Below-average household monthly income ( $v$ about-or-above average) & N/A & N/A & $N / A$ & N/A \\
\hline
\end{tabular}

Note: NA refers to not applicable as those variables were dropped out from the analysis by default of the software due to perfect prediction of outcome.

Buddhism, and living in a more affluent household, despite the fact that these factors seemed to lose a statistical significance in multivariable analysis. Asian URAS tended to enjoy NCD services at a greater extent than non-Asian URAS.

The difference in NCD access between Asian and nonAsian URAS might be a result of cultural differences. Asian URAS were likely to get used to the culture and living conditions in Thailand rather than non-Asian URAS because Thai culture has blended with culture from neighbouring countries as well as China and India for quite a long time. Similarly, several studies revealed that the ability to adapt to cultures and lifestyles in the destination country has positive effect on the health status and quality of life of migrants and refugees. ${ }^{37-39}$ The lack of health insurance in URAS caused them to face financial difficulties due to out-of-pocket payments when seeking treatment. Unlike URAS, all Thais are having health insurance, according to the law. Our findings (Table 3) suggested that being insured displayed a positive correlation with increasing access to NCD health services (even though the statistical significance was presented only in univariable analysis). Not accessing services was more common in less affluent households and non-Buddhist participants, who were more prevalent among URAS. ${ }^{40,41}$ These factors help explain why URAS with some characteristics were more likely to face barriers in accessing services than others (for example, those living in the less well-off household could not afford buying the insurance or those conforming to non-Buddhist religions might be less familiar with the Thai culture).

Our findings, to a certain extent, indicated some gaps in policies. Firstly, the majority of URAS were uninsured by any insurance scheme and the low volume of access to NCD services reflects that Thailand has not truly achieved the Universal Health Coverage (UHC) as intended. ${ }^{42,43}$ The Thai government should consider expanding health coverage to URAS. Experiences of extending the insurance coverage for URAS in other countries, such as Malaysia and Iraq, are worth exploring. ${ }^{44,45}$ Secondly, the mental health burden among URAS was huge compared with other diseases. The Department of Mental Health of the MOPH should work closely with civic groups and play a more proactive role in providing mentalhealth care for URAS rather than waiting for URAS to turn up at health facilities. Thirdly, culturally appropriate healthcare systems should be taken into account to overcome cultural barriers, especially among URAS originating from non-Asian nations. Much literature suggests integrating culturally sensitive care with the healthcare system of the host country to bridge diverse understandings between URAS (or any minorities in the society) and formal healthcare providers. ${ }^{46-48}$ Of note is that, in multivariable analysis, many predictor variables lost a statistical significance though the direction of association did not change much from the bivariate analysis. This alluded to 
the fact that the variables included in the analysis had some latent factors lying inside. Such factors might not be expressed explicitly in the questionnaire. The likely factors might be related to mistrust in the system, travelling difficulties, or fear of being captured by police or security officers. Further qualitative research on these issues is recommended as it can provide better insights and increase the explanation power of the quantitative analysis in this study.

Some limitations remained. Firstly, URAS have a variety of nationalities and languages. It is difficult to guarantee that all questionnaire translation is completely correct. However, we have attempted to reduce the bias by holding the meeting between BRC volunteer staff who served as interpreters in case the participants did not understand the questionnaire fully. Secondly, questions asked about a person's history of healthcare visits. Thus, some degree of memory bias was inevitable. Thirdly, there was no physical visit to households during the interview due to the URAS' need for confidentiality. Therefore, it was not possible to directly assess the economic status of the URAS' households. Fourthly, the survey on URAS and Thai participants happened in different timeframes despite using the same set of questions. However, the time difference between both surveys was less than a year and in 2019 there was no significant change in the Thai healthcare system. This meant the information bias which originated from this might be minimal. Fifthly, this study used a cross-sectional approach. Therefore, we could not firmly determine the causal inference between the factors of interest and the incidence of access to NCD health services. Neither could we explore the changes in health over time which are definitely influenced by various factors including the COVID-19 pandemic. Lastly, the generalisability power of this study was limited as we included only URAS in the BRC roster, and not all URAS in Thailand (though the main residential address of many URAS was in Bangkok). Additional studies on refugees in other settings (such as detention centers or temporary sheltered areas) and on other specific diseases (such as communicable diseases, injuries, and mental health) are recommended in order to expand the academic knowledge in this field. This include studies on both prevalence, incidence, and causes of certain diseases. More advanced methods, for instance, a multiple imputation method, should be exercised to deal with records that might be caused by missing data.

\section{Conclusion}

Overall, URAS were younger, had lower education, and greater financial hardship than Thais. The prevalence of NCD in URAS was similar to that in Thais, however, the prevalence of mental health illness was significantly higher in URAS. Almost half of URAS did not receive NCD care at formal health facilities. Factors that demonstrated a positive relationship with access to NCD services were being insured, being Buddhist, and having a more affluent household economy. URAS from Asian countries were more likely to use NCD services than URAS from non-Asian countries. The Thai government should consider expanding the insurance coverage to URAS, which may prevent public health threats, not only for URAS communities but for Thai society as a whole. Further studies on the health of other types of refugees and on other diseases apart from NCDs are recommended.

\section{Abbreviations}

BRC, Bangkok Refugee Centre; CI, Confidence interval; CLMV, Cambodia, Lao PDR, Myanmar, and Viet Nam; HAUS, Health Access and Utilization Survey; HWS, Health Welfare Survey; MOPH, Ministry of Public Health; NCD, Noncommunicable diseases; NGOs, Nongovernmental organizations; NSO, National Statistical Office; OR, Odd ratios; PPS, Probability proportional to size; SEAR, South-East Asia Region; UHC, Universal Health Coverage; UNHCR, United Nations High Commissioner for Refugees; URAS, Urban refugees and asylum seekers; WHA, World Health Assembly.

\section{Ethics Approval and Informed Consent}

The ethical approval was obtained from the Institute for the Development of Human Research Protections (IHRP) -letterhead: IHRP 592/2562. IHRP is an official institute which is responsible for ethical review and supervision for human research. The research which is approved by the IHRP has to be academic valid and conducted following the Declaration of Helsinki. The data collection process of this study strictly followed the Declaration of Helsinki. The informed consent process in this study was firmly approved by IHRP. All participants obtained written consent, and for those who were uncomfortable with written consent, verbal consent was used instead. All participants participated in this study voluntarily and had the right to withdraw from the survey. All information was kept confidential and was reported as anonymous. 


\section{Acknowledgments}

We are grateful for the support from BRC, IHPP and UNHCR during the survey process. The advice from Ms Bongkot Napaumporn and Dr Herve Isambert is hugely appreciated.

\section{Author Contributions}

All authors made a significant contribution to the work reported, whether that is in the conception, study design, execution, acquisition of data, analysis and interpretation, or in all these areas; took part in drafting, revising or critically reviewing the article; gave final approval of the version to be published; have agreed on the journal to which the article has been submitted; and agree to be accountable for all aspects of the work.

\section{Funding}

The publication fee of this article was supported by the Health Systems Research Institute (HSRI), Thailand.

\section{Disclosure}

The authors declare that they have no competing interests in this work.

\section{References}

1. United Nations. International migration report 2017 Highlights (ST/ ESA/SER.A/404). New York: United Nations; 2017. Available from: http://www.un.org/en/development/desa/population/migration/publica tions/migrationreport/docs/MigrationReport2017_Highlights.pdf. Accessed August 12, 2021.

2. UNHCR. Figures at a glance: statistical yearbooks. Geneva: UNHCR; 2018. Available from: https://www.unhcr.org/figures-at-a-glance.html. Accessed August 12, 2021.

3. World Vision. Syrian refugee crisis: facts, FAQs, and how to help. Washington: World Vision; 2019. Available from: https://www.worldvi sion.org/refugees-news-stories/syrian-refugee-crisis-facts. Accessed August 12, 2021.

4. European Commission. The Rohingya crisis: ECHO factsheet. Brussels: European Commission; 2018. Available from: http://ec. europa.eu/echo/files/aid/countries/factsheets/rohingya_en.pdf.

Accessed August 12, 2021.

5. World Health Organization. Promoting the health of refugees and migrants. Seventieth world health assembly resolution WHA70.15, 31 May 2017. Geneva: World Health Organization; 2017. Available from: www.who.int/migrants/about/A70_R15-en.pdf. Accessed August 12, 2021.

6. UNHCR. New York declaration for refugees and migrants. New York: UNHCR; 2019. Available from: https://www.unher.org/new-yorkdeclaration-for-refugees-and-migrants.html. Accessed August 12, 2021.

7. United Nations. Global compact for migration. New York: United Nations; 2018. Available from: https://refugeesmigrants.un.org/migra tion-compact. Accessed August 12, 2021.

8. United Nations. Global compact on refugees. New York: United Nations; 2018. Available from: https://www.unhcr.org/5c658aed4.pdf. Accessed August 12, 2021.
9. United Nations Thematic Working Group on Migration in Thailand. Thailand migration report 2019. Bangkok, Thailand. 2019.

10. Alexakis LC, Athanasiou M, Konstantinou A. Refugee camp health services utilisation by non-camp residents as an indicator of unaddressed health needs of surrounding populations: a perspective from Mae La refugee camp in Thailand during 2006 and 2007. Pan Afr Med J. 2019;32:188. doi:10.11604/pamj.2019.32.188.16780

11. Plewes K, Lee T, Kajeechewa L, et al. Low seroprevalence of HIV and syphilis in pregnant women in refugee camps on the Thai-Burma border. Int J STD AIDS. 2008;19(12):833-837. doi:10.1258/ijsa.2008.008034

12. Kangkun P. Life in limbo for Thailand's urban refugees. Bangkok: Nation Thailand; 2018. Available from: https://www.nationthailand. com/opinion/30355070. Accessed August 12, 2021.

13. World Health Organization. Noncommunicable diseases progress monitor 2020; 2020. Available from: https://www.who.int/publica tions-detail/ncd-progress-monitor-2020. Accessed August 12, 2021.

14. WHO Department of Communications. Noncommunicable diseases prematurely take 16 million lives annually, WHO urges more action 2015 [updated 19 JANUARY 2015]. Available from: https://www. who.int/mediacentre/news/releases/2015/noncommunicable-diseases /en/. Accessed August 12, 2021.

15. Mahipala P, Dorji G, Tisocki K, Rani M. A critical review of addressing cardiovascular and other non-communicable diseases through a primary health care approach in the South-East Asia Region. Cardiovasc Diagn Ther. 2019;9(2):150-157. doi:10.21037/ cdt.2018.09.03

16. World Health Organization. Noncommunicable diseases country profiles 2018 [233]. Available from: https://www.who.int $/ \mathrm{nmh} /$ publica tions/ncd-profiles-2018/en/. Accessed August 12, 2021.

17. Vaage AB, Thomsen PH, Silove D, Wentzel-Larsen T, Van Ta T, Hauff E. Long-term mental health of Vietnamese refugees in the aftermath of trauma. $B r \quad J \quad$ Psychiatr. 2010;196(2):122-125. doi:10.1192/bjp.bp.108.059139

18. Giallo R, Riggs E, Lynch C, et al. The physical and mental health problems of refugee and migrant fathers: findings from an Australian population-based study of children and their families. BMJ Open. 2017;7(11):e015603. doi:10.1136/bmjopen-2016-015603

19. Abbas M, Aloudat T, Bartolomei J, et al. Migrant and refugee populations: a public health and policy perspective on a continuing global crisis. Antimicrob Resist Infect Control. 2018;7(1):1-11. doi:10.1186/s13756-018-0403-4

20. Palinkas LA, Pickwell SM. Acculturation as a risk factor for chronic disease among Cambodian refugees in the United States. Soc Sci Med. 1995;40(12):1643-1653. doi:10.1016/0277-9536(94)00344-S

21. Carlsson JM, Olsen DR, Mortensen EL, Kastrup M. Mental health and health-related quality of life: a 10-year follow-up of tortured refugees. J Nerv Ment Dis. 2006;194(10):725-731. doi:10.1097/01. nmd.0000243079.52138.b7

22. Popkin BM, Udry JR. Adolescent obesity increases significantly in second and third generation US immigrants: the National Longitudinal Study of Adolescent Health. J Nutr. 1998;128 (4):701-706. doi:10.1093/jn/128.4.701

23. Lears LO, Abbott JS. The most vulnerable among us. Health Progress (Saint Louis, Mo). 2005;86(1):22-25, 60.

24. Mowafi H. Conflict, displacement and health in the Middle East. Glob Public Health. 2011;6(5):472-487. doi:10.1080/17441692.2011.570358

25. Mowafi $H$, Spiegel P. The Iraqi refugee crisis: familiar problems and new challenges. JAMA. 2008;299(14):1713-1715. doi:10.1001/ jama.299.14.1713

26. Amara AH, Aljunid SM. Noncommunicable diseases among urban refugees and asylum-seekers in developing countries: a neglected health care need. Global Health. 2014;10(1):24. doi:10.1186/1744-8603-10-24

27. Doocy S, Lyles E, Roberton T, Akhu-Zaheya L, Oweis A, Burnham G. Prevalence and care-seeking for chronic diseases among Syrian refugees in Jordan. BMC Public Health. 2015;15 (1):1097. doi:10.1186/s12889-015-2429-3 
28. Rehr M, Shoaib M, Ellithy S, et al. Prevalence of non-communicable diseases and access to care among non-camp Syrian refugees in northern Jordan. Confl Health. 2018;12(1):33. doi:10.1186/s13031-018-0168-7

29. Marshall SJ. Developing countries face double burden of disease. Bull World Health Organ. 2004;82(7):556.

30. Napoli C, Dente MG, Kärki T, Riccardo F, Rossi P, Declich S. Screening for infectious diseases among newly arrived migrants: experiences and practices in non-EU countries of the mediterranean basin and black sea. Int $J$ Environ Res Public Health. 2015;12 (12):15550-15558. doi:10.3390/ijerph121215002

31. Ackerman LK. Health problems of refugees. J Am Board Fam Pract. 1997;10(5):337-348.

32. Bureau of Non-Communicable Diseases DoDc. Situation on NCDs Prevention and Control in Thailand. Nonthaburi, Thailand: Department of Disease control, Ministry of Public Health; 2018.

33. National Statistical Office. Revenue and household expenditure. Bangkok: NSO; 2020. Available from: http://statbbi.nso.go.th/staticre port/page/sector/th/08.aspx. Accessed August 12, 2021.

34. Shawyer F, Enticott JC, Block AA, Cheng IH, Meadows GN. The mental health status of refugees and asylum seekers attending a refugee health clinic including comparisons with a matched sample of Australian-born residents. BMC Psychiatr. 2017;17(1):76 doi:10.1186/s12888-017-1239-9

35. Taylor EM, Yanni EA, Pezzi C, et al. Physical and mental health status of Iraqi refugees resettled in the United States. J Immigr Minor Health. 2014;16(6):1130-1137. doi:10.1007/s10903-013-9893-6

36. UNHCR Malaysia. At a Glance: Health Access and Utilization Survey Among Non-Camp Refugees in Malaysia. Malaysia: UNHCR; 2015.

37. Schwartz SJ, Unger JB, Zamboanga BL, Szapocznik J. Rethinking the concept of acculturation: implications for theory and research. $\mathrm{Am}$ Psychol. 2010;65(4):237-251. doi:10.1037/a0019330

38. Lincoln AK, Lazarevic V, White MT, Ellis BH. The impact of acculturation style and acculturative hassles on the mental health of Somali adolescent refugees. J Immigr Minor Health. 2016;18 (4):771-778. doi:10.1007/s10903-015-0232-y

39. Young M. [Acculturation, identity and well-being: the adjustment of Somalian refugees]. Sante Ment Que. 1996;21(1):271-290. French. doi:10.7202/032391ar
40. Suphanchaimat R, Sinam P, Phaiyarom M, et al. A cross sectional study of unmet need for health services amongst urban refugees and asylum seekers in Thailand in comparison with Thai population, 2019. Int J Equity Health. 2020;19:1-2. doi:10.1186/s12939-02001316-y

41. O'Donnell O. Access to health care in developing countries: breaking down demand side barriers. Cadernos De Saúde Pública. 2007;23:2820-2834. doi:10.1590/S0102-311X2007001200003

42. National Health Security Office. NHSO vision/mission. Bangkok: NHSO; 2020. Available from: http://eng.nhso.go.th/view/1/Vision Mission/EN-US. Accessed August 12, 2021.

43. Witthayapipopsakul W, Kulthanmanusorn A, Vongmongkol V, Viriyathorn S, Wanwong Y, Tangcharoensathien V. Achieving the targets for universal health coverage: how is Thailand monitoring progress? WHO South East Asia J Public Health. 2019;8:10-17. doi:10.4103/2224-3151.255343

44. Matlin SA, Depoux A, Schütte S, Flahault A, Saso L. Migrants' and refugees' health: towards an agenda of solutions. Public Health Rev. 2018;39:27. doi:10.1186/s40985-018-0104-9

45. Chuah FLH, Tan ST, Yeo J, Legido-Quigley H. Health system responses to the health needs of refugees and asylum-seekers in Malaysia: a qualitative study. Int $J$ Environ Res Public Health. 2019;16(9):1584. doi:10.3390/ijerph16091584

46. Mangrio E, Sjögren Forss K. Refugees' experiences of healthcare in the host country: a scoping review. BMC Health Serv Res. 2017;17 (1):814. doi:10.1186/s12913-017-2731-0

47. Fang ML, Sixsmith J, Lawthom R, Mountian I, Shahrin A. Experiencing 'pathologized presence and normalized absence'; understanding health related experiences and access to health care among Iraqi and Somali asylum seekers, refugees and persons without legal status. BMC Public Health. 2015;15:923. doi:10.1186/ s12889-015-2279-z

48. Omeri A, Lennings C, Raymond L. Beyond asylum: implications for nursing and health care delivery for Afghan refugees in Australia. J Transcult Nurs. 2006;17(1):30-39. doi:10.1177/ 1043659605281973
Risk Management and Healthcare Policy

\section{Publish your work in this journal}

Risk Management and Healthcare Policy is an international, peerreviewed, open access journal focusing on all aspects of public health, policy, and preventative measures to promote good health and improve morbidity and mortality in the population. The journal welcomes submitted papers covering original research, basic science, clinical \& epidemiological studies, reviews and evaluations, guidelines, expert opinion and commentary, case reports and extended reports. The manuscript management system is completely online and includes a very quick and fair peer-review system, which is all easy to use. Visit http://www.dovepress.com/testimonials.php to read real quotes from published authors. 